\title{
The times they are a-changin'
}

\section{Hindrik Mulder ${ }^{1}$}

Published online: 4 November 2020

(C) Springer-Verlag GmbH Germany, part of Springer Nature 2020

Editors-in-Chief (EiCs) at Diabetologia serve a 3 year term of office with an optional 2-3 year extension. Time moves quickly - it is now time for the outstanding Sally Marshall to hand over the baton to her successor, which is...me!

I have been involved in diabetes research for nearly 30 years. Indeed, the third paper I ever published was in Diabetologia in 1995 and I recall how excited my senior coauthors were by the fact that we had a paper accepted in the journal. It took some time, learning about publication, reputation of journals, impact and citations, before I fully appreciated why publishing in Diabetologia is so prestigious. Had anyone suggested back then that, one day, I would become the EiC of the journal, I would have laughed at the prospect of such an honour being bestowed on me. But now, here we are. It is truly an honour, given the outstanding research and leadership that the journal represents, not to mention the exceptional EiCs that have gone before, the fantastic Associate Editors and the amazing editorial staff in Bristol.

So, who do you get? I grew up in a Dutch family that relocated to Sweden in 1962 to allow my father to pursue a career in the pharmaceutical industry. Hence, medical research has been engrained in me since childhood, as has a global perspective of the world, where mobility is key. This necessitates respect for, and understanding of, different cultures and points of view.

Very early, I decided that I wanted to become a medical doctor. I received my MD from Lund University in 1988 and became licensed to practise medicine in 1992. I remain passionate about my clinical work, which currently involves a diabetes outpatient clinic once a week at the Endocrinology Department at Skåne University Hospital in Malmö, Sweden. The input I receive from my patients and clinical colleagues constantly challenges my view of the disease and provides perspective on my research.

Hindrik Mulder

hindrik.mulder@med.lu.se

1 Unit of Molecular Metabolism, Lund University Diabetes Centre, Malmö, Sweden
My research has always focused on diabetes, foremost type 2 diabetes. Initially, my work was experimental and basic but, over time, the desire to do translational research has grown much stronger. My focus, initially on beta cells and islets, has expanded to whole-body physiology and functional genomics, and involves both animal and human studies. The very best research, in my view, tells a story; my most cherished work has begun with a mechanism or a genetic finding that, through a series of interdisciplinary studies, becomes relevant for the patient. The term 'bench to bedside and back' may seem clichéd, but it very much embodies the way I do my research. Such an approach cannot be achieved by a solitary scientist: it is only possible within the framework of a gracious and generous collaborative environment. It has been my great fortune to be part of, and to now contribute to the leadership of the Lund University Diabetes Centre (Malmö, Sweden).

If 'collaboration' is my first mantra, then the second would be 'mentors'. My first mentor, Frank Sundler, instilled in me that curiosity is a crucial driving force in science; Frank also taught me the important 'do's and don'ts' of research. With the early guidance from Bo Ahrén, my understanding of diabetes expanded and deepened. I had the great privilege of being a postdoctoral fellow at the Diabetes Center at UT Southwestern in Dallas (TX, USA) in the late 1990s, which was an extraordinary and exciting place to be at the time, with luminaries such as Denis McGarry, Roger Unger, Chris Newgard and Chris Rhodes. It profoundly changed my view on research. The limits of our achievements are often set by our imagination and our willingness to strive for what we believe in. At UT Southwestern, I never heard 'this cannot be done'; instead I was told to 'figure out how to do it'. Another mentor, Chris Newgard, said, 'You go where the science takes you'. Chris also proved to be a wonderful and inspiring example of an outstanding group leader, both scientifically and socially; indeed, neglecting the latter can often be at the cost of the former. Upon returning to Sweden and Lund, Cecilia Holm welcomed me into her laboratory and allowed me to gain my independence, and Leif Groop included me as a part of the diabetes research environment at Lund University; this was yet another game changer for me. Leif's understanding of human physiology, diabetes, and the role that genetics 
and the environment play to trigger and exacerbate diabetes forever changed my scientific world. Besides his monumental scientific achievements, Leif developed a vibrant metabolic research environment that allowed me to work side by side with exceptional peers from around the world; this experience instilled in me a deep sense of privilege and humility. As I have grown in seniority, this has been reinforced by the many inspiring interactions I have had with remarkable students and fellows.

Diabetologia is a true core journal in diabetes and metabolism. Under Sally's dynamic leadership, it has also reached its highest impact factor ever. More importantly, so many testify to its courteous and fair handling of authors and reviewers with a personal touch, a much-welcomed relief in this age of clicks and automated messages.

Despite these successes, the journal cannot rest on its laurels. The overarching role of the journal is to serve the scientific community, which is on the quest for knowledge for the good of humanity, society and patients. To fulfil this role, the journal must be attuned to the scientific community and its taskmasters. Science, and the way it is conducted and presented, changes with great speed. A few years back, who would have predicted that large scientific meetings could be held successfully in a virtual space, that a large proportion of excellent science first sees the light of day in preprint archives, that many scientists today communicate scientific information on digital platforms, or that crowd sourcing and citizen science would emerge as novel ways to conduct research? With respect to how diabetes is defined and described, we are currently seeing profound changes. Precision medicine for diabetes, bringing with it big-data analyses that help to unravel the heterogeneity of the disease and yield novel biomarkers of high value to clinicians, may be just around the corner. All of this will no doubt drive the publishing agenda for Diabetologia in the coming years. Thus, our task will remain unchanged: serving the scientific community. However, the way we do it will continue to evolve, because science and its relationship with the world around us is in constant flux.

While change may sound intimidating to some, it also offers a great opportunity. It will allow the journal to improve further and become even more relevant as a conduit for scientific output. I am confident that Diabetologia will be able to operate in this fashion because we have an outstanding team of Associate Editors, with their fingers on the pulse of today's and tomorrow's science, as well as an outstanding and professional editorial team. I will bring my passion for science, my understanding of the power of working together and my will to learn to Diabetologia.

Publisher's note Springer Nature remains neutral with regard to jurisdictional claims in published maps and institutional affiliations. 